\title{
Erratum to: Superposition states for quantum nanoelectronic circuits and their nonclassical properties
}

\author{
Jeong Ryeol Choi ${ }^{1}$
}

Published online: 9 December 2016

(c) The Author(s) 2016. This article is published with open access at Springerlink.com

\section{Erratum to: Int Nano Lett \\ DOI 10.1007/s40089-016-0191-x}

The original version of this article unfortunately contained some errors.

(1) Correct version of Eq. (24)

$$
\begin{aligned}
\hat{D}(\alpha)= & \exp \left(-i \frac{Q_{\mathrm{t}, c}(0) P_{\mathrm{t}, c}(0)}{2 \hbar}\right) \exp \left(i \frac{P_{\mathrm{t}, c}(0) \hat{q}}{\hbar}\right) \\
& \times \exp \left(-i \frac{Q_{\mathrm{t}, c}(0) \hat{p}}{\hbar}\right) .
\end{aligned}
$$

(2) First line on page 5 (right).

[Old]: ... represent $\rho(t)$ as $\rho_{0} f(t)$ without loss of generality, ...

[New]: ... represent $\rho(t)$ as $\rho_{0} f(t)$ without loss of generality, ...

(3) Line 4 on page 8 (left).

[Old]: ... Research Program of the year 2015 through the National ...

[New]: ... Research Program through the National ...
(4) Reference 23 on page 9.

[Old]: ... Generation of optical Schrödinger cats from photon number ...

[New]: ... Generation of optical 'Schrödinger cats' from photon number ...

(5) Line 23 on page 7 (right).

[Old]: By comparing Fig. 2c, with Fig. 2a, we can make out ...

[New]: By comparing Fig. 2c with Fig. 2a, we can make out ...

(6) Line 31 on page 7 (right).

[Old]: From Figs. 1, 2 and 3, you can see interference ...

[New]: From Figs. 1, 2, and 3, you can see interference ...

Open Access This article is distributed under the terms of the Creative Commons Attribution 4.0 International License (http://crea tivecommons.org/licenses/by/4.0/), which permits unrestricted use, distribution, and reproduction in any medium, provided you give appropriate credit to the original author(s) and the source, provide a link to the Creative Commons license, and indicate if changes were made.

The online version of the original article can be found under doi:10.1007/s40089-016-0191-x.

Jeong Ryeol Choi

choiardor@hanmail.net

1 Department of Radiologic Technology, Daegu Health College, Yeongsong-ro 15, Buk-gu, Daegu 41453, Republic of Korea 